\title{
Effect of Academic-related Factors on Adjustment Problems in Adolescents
}

\author{
Rajkumar G', Saravanan $\mathbf{M}^{2}$, Anbarasi $\mathbf{M}^{3}$ \\ ${ }^{1}$ Dr Rajkumar G, Associate Professor of Paediatrics, Dhanalakshmi Srinivasan Medical College and Hospital, \\ Perambalur, ${ }^{2}$ Dr Saravanan M, Assistant Professor of Paediatrics, Vellammal Medical College Hospital and Research \\ Institute, Madurai, ${ }^{3}$ Dr Anbarasi M, Associate Professor of Physiology, Dhanalakshmi Srinivasan Medical College and \\ Hospital, Tiruchi -Chennai Highway, Siruvachur, Perambalur, Tamil Nadu 621113, India.
}

Address for Correspondence: Dr. G. Rajkumar, Paediatrics, Associate Professor of Paediatrics, Dhanalakshmi Srinivasan Medical College and Hospital, Siruvachur, Perambalur. Email: grkmedico@outlook.com, grkmedico@gmail.com.

\begin{abstract}
Background: Adolescence is the period of stressful transition from childhood to adults which provides opportunity to a lot of adjustment problems. This study is intended to assess the mental health in adolescents and their adjustment, using standardised questionnaires. Materials and Methods: This is a descriptive, cross-sectional study involving 175 school students of both genders and of age ranging from 14 to 17 . After getting clearance from Institutional ethics committee and consent from the parents, the students were administered a socio-demographic proforma, General Health Questionnaire-28 (GHQ-28) and Adjustment Inventory for School Students (AISS) by one-to-one interview method. The scores were analysed statistically with Student's independent t test using SPSS 20.0. Results and Discussion: There was significant increase in social dysfunction $(\mathrm{p}=0.03)$ and poor adjustment in all categories $(\mathrm{p}<0.05)$ as age advanced. Government school students showed more somatic symptoms $(p=0.03)$ than the private schools, while private school students showed poor educational adjustment $(\mathrm{p}=0.01)$. Students from English medium had significant social dysfunction when compared to those from Tamil medium $(\mathrm{p}=0.03)$. Day scholars showed poor social dysfunction, while hostellers showed poorer social and overall adjustment. There was correlation between mental health and adjustment with poor mental health leading to poor adjustment. Conclusion: Factors like increasing age, type of school, medium of instruction and type of accommodation is significantly affecting the coping nature of the adjustment related problems.
\end{abstract}

Keywords: Adolescence, Mental Health, Adjustment, Students

\section{Introduction}

Adolescence is a transition from childhood to adults wherein children feel a great storm and stress from various aspects [1]. They are expected to be behaving like adults while they are still longing for their childhood wishes from inside. This internal conflict, when overcome by proper guidance and support from all sectors leads to successful adolescence. Where such guidance is lacking, this transition period ends up in severe adjustment problems ranging from depression, scholastic backwardness and even anti-social behaviour.

Adolescent population is about one fourth of the total population of India which constitutes about $20 \%$ of

Manuscript received: $2^{\text {nd }}$ August 2016

Reviewed: $13^{\text {th }}$ August 2016

Author Corrected; $24^{\text {th }}$ August 2016

Accepted for Publication: $9^{\text {th }}$ September 2016 world's population [2]. Researchers suggest that more young people are suffering from mental health problems because they perceive more stress and are incapable of coping with stress. According to WHO, an overall prevalence rate of about $20 \%$ has been documented for child and adolescent mental disorders, while Indian Council of Medical Research reported that about 12.8 per cent of children (1-16 years) suffer from mental health problems in India [3]. A metaanalyis by Malhotra et al [4] have concluded that the prevalence rate of child and adolescent psychiatric problems in the community is about $6.46 \%$ and in the school, it is about $23.33 \%$.

Menninger (1945) defined mental health as the adjustment of human beings to the world and to each 
other with a maximum of effectiveness and happiness [5]. Mental health is the ability to maintain an even temper, an alert intelligence, socially considerate behaviour with cheerfulness.

Mental health can be described as absence of symptoms of maladjustment, be they mild or severe. Mentally healthy person is free from all types of maladjustment [6].

The Adjustment Inventory for School Students (AISS), [7] designed by A.K.P Sinha and R.P Singh is a selfreport inventory which seeks to segregate well-adjusted secondary school students (age group 14 to 18 years) from poorly adjusted students in the three areas of adjustment- Emotional, Social and Educational domains. The inventory consists of 60 items, 20 items for each area of adjustment.

The General Health Questionnaire - 28 (GHQ-28) [8] is used to detect psychiatric disorder in the general population and within community or non-psychiatric clinical settings such as primary care or general medical out-patients. It assesses the respondent's current state and asks if that differs from his or her usual state.

It is therefore sensitive to short-term psychiatric disorders but not for long-standing attributes of the respondent.

The present study was aimed at exploring the academicrelated factors influencing the adjustment problems and to correlate them with the mental health of secondary school students.

\section{Materials and Methods}

This is a descriptive, cross-sectional study involving 175 school students of both genders and of age ranging from 14 to 17 . The study was started after getting clearance from Institutional ethics board of Chennai Medical College Hospital and Research Centre.

The study participants were recruited from both government and private schools by using convenient sampling method after getting consent from their parents and permission from their school Principals.
Students who were on treatment for any proven psychological or psychiatric disorder were excluded from the study.

After a brief introduction by the investigator the students were asked to fill the socio- demographic Profoma.

The students were made to answer for GHQ-28 and AISS on one-to-one interview method after clearly understanding the meaning of questions. They were also emphasized that there were no right or wrong answers.

Scoring of GHQ-28 [8]: This 'scaled' version of the GHQ has been developed on the basis of the results of principal components analysis.

The four sub-scales, each containing seven items, are as follows: A - Somatic symptoms (items 1-7); B anxiety/insomnia (items 8-14); C - Social dysfunction (items 15-21); D - Severe depression (items 22-28).

For identifying caseness with GHQ-28, the total of the sub-scales is used. GHQ scoring (0-0-1-1) for positive items, where agreement indicates health, and 0-1-1-1 for negative items, where agreement indicates illness. The higher the score, the more severe is the condition.

Scoring of AISS [7]: The total score on adjustment is obtained by summing the individual domain scores that indicates the general adjustment status.

Scores greater than 11 on the emotional domain indicates unstable emotions while low scores indicate stable emotions. Individuals with scores greater than 11, on the social adjustment domain indicate that they are submissive and revering.

Scores greater than 11 on the educational domain indicates that adolescents are poorly adjusted with their curricular and co-curricular programs while low scores indicative that they have interest in school programs.

Statistical analysis- After collection of the data, results were analyzed using independent $\mathrm{T}$ test and One way ANOVA using SPSS 20.0.

\section{Results}

Table 1 shows the percentage analysis of the baseline characteristics and socio-demographic details of the 175 study participants. The participants have been categorized based on age, gender, type of school, medium of instruction and type of accommodation. 
Table-1: Socio-demographic details of the study participants.

\begin{tabular}{|c|c|c|}
\hline S.No & Characteristics & n (\%) \\
\hline 1. & \multicolumn{2}{|c|}{ Age } \\
\hline & 14 & $49(28)$ \\
\hline & 15 & $39(22.3)$ \\
\hline & 16 & $49(28)$ \\
\hline & 17 & $38(21.7)$ \\
\hline \multirow[t]{3}{*}{2.} & Gender & \\
\hline & Boys & $90(51.4)$ \\
\hline & Girls & $85(48.6)$ \\
\hline 3. & \multicolumn{2}{|c|}{ School type } \\
\hline & Government & $70(40)$ \\
\hline & Private & $105(60)$ \\
\hline \multirow[t]{3}{*}{4.} & \multicolumn{2}{|c|}{ Medium of education } \\
\hline & English & $100(57.1)$ \\
\hline & Tamil & $75(42.9)$ \\
\hline 5. & \multicolumn{2}{|c|}{ Type of accommodation } \\
\hline & Day scholar & $110(62.9)$ \\
\hline & Hosteller & $65(37.1)$ \\
\hline
\end{tabular}

Table 2. shows the age-wise comparison of GHQ and adjustment scale using one-way ANOVA which clearly shows that as age increases the social dysfunction scores of GHQ increases $(p=0.03)$. Also, there was poor adjustment scores in AISS as age advances ( $\mathrm{p}=0.007$ for overall adjustment score).

Table-2: Age-wise comparison of GHQ and Adjustment scale.

\begin{tabular}{|c|c|c|c|c|c|}
\hline Type of scale & $\begin{array}{c}\mathbf{1 4} \\
\mathbf{n}=\mathbf{4 9}\end{array}$ & $\begin{array}{c}\mathbf{1 5} \\
\mathbf{n}=\mathbf{3 9}\end{array}$ & $\begin{array}{c}\mathbf{1 6} \\
\mathbf{n}=\mathbf{4 9}\end{array}$ & $\begin{array}{c}\mathbf{1 7} \\
\mathbf{n}=\mathbf{3 8}\end{array}$ & $\mathbf{p}$ value \\
\hline $\begin{array}{c}\text { GHQ somatic } \\
\text { symptoms }\end{array}$ & $1.71 \pm 0.456$ & $1.69 \pm 0.468$ & $1.55 \pm 0.503$ & $1.79 \pm 0.413$ & 0.106 \\
\hline $\begin{array}{c}\text { GHQ anxiety } \\
\text { insomnia }\end{array}$ & $1.88 \pm 0.331$ & $1.87 \pm 0.339$ & $1.84 \pm 0.373$ & $1.71 \pm 0.460$ & 0.167 \\
\hline $\begin{array}{c}\text { GHQ social } \\
\text { dysfunction }\end{array}$ & $1.18 \pm 0.391$ & $1.08 \pm 0.270$ & $1.18 \pm 0.391$ & $1.34 \pm 0.481$ & $0.031^{*}$ \\
\hline $\begin{array}{c}\text { GHQ severe } \\
\text { depression }\end{array}$ & $1.90 \pm 0.306$ & $1.77 \pm 0.427$ & $1.86 \pm 0.612$ & $1.89 \pm 0.311$ & 0.521 \\
\hline $\begin{array}{c}\text { AISS emotional } \\
\text { adjustment }\end{array}$ & $3.49 \pm 0.916$ & $3.79 \pm 0.801$ & $3.80 \pm 0.841$ & $4.03 \pm 0.753$ & $0.030^{*}$ \\
\hline $\begin{array}{c}\text { AISS social } \\
\text { adjustment }\end{array}$ & $3.61 \pm 0.702$ & $3.77 \pm 0.627$ & $3.84 \pm 0.717$ & $4.08 \pm 0.673$ & $0.019^{*}$ \\
\hline $\begin{array}{c}\text { AISS educational } \\
\text { adjustment }\end{array}$ & $4.00 \pm 0.764$ & $4.38 \pm 0.673$ & $4.43 \pm 0.736$ & $4.16 \pm 0.679$ & $0.014^{*}$ \\
\hline AISS overall score & $3.67 \pm 0.630$ & $4.00 \pm 0.562$ & $4.08 \pm 0.702$ & $4.05 \pm 0.655$ & $0.007^{*}$ \\
\hline
\end{tabular}

*statistically significant by one-way ANOVA.

Table 3 compiles the significance of variable factors related to school environment which affect GHQ and AISS. This analysis was done using student's independent $t$ test. Students of government schools showed more somatic symptoms $(\mathrm{p}=0.03)$ while private school students showed poor educational adjustments $(\mathrm{p}=0.01)$.

Students with English as medium of instruction had significant social dysfunction than students with Tamil as medium of instruction $(\mathrm{p}=0.03)$. Dayscholars showed poor social dysfunction scores of GHQ $(\mathrm{p}=0.02)$. 
Table-3: Significant variables affecting GHQ and Adjustment scale.

\begin{tabular}{|c|c|c|c|c|c|}
\hline Variable & Type of scale & & Mean \pm SD & T test & P value \\
\hline \multirow{4}{*}{$\begin{array}{l}\text { Type of } \\
\text { school }\end{array}$} & \multirow{2}{*}{$\begin{array}{l}\text { GHQ somatic } \\
\text { symptoms }\end{array}$} & Government $(\mathrm{n}=70)$ & $1.77 \pm 0.423$ & \multirow{2}{*}{2.132} & \multirow{2}{*}{$0.034 *$} \\
\hline & & Private $(n=105)$ & $1.62 \pm 0.488$ & & \\
\hline & \multirow{2}{*}{$\begin{array}{c}\text { AISS educational } \\
\text { adjustment }\end{array}$} & Government $(n=70)$ & $4.07 \pm 0.748$ & \multirow{2}{*}{2.516} & \multirow{2}{*}{$0.013^{*}$} \\
\hline & & Private $(n=105)$ & $4.35 \pm 0.707$ & & \\
\hline \multirow{2}{*}{$\begin{array}{l}\text { Medium of } \\
\text { instruction }\end{array}$} & \multirow{2}{*}{$\begin{array}{l}\text { GHQ social } \\
\text { dysfunction }\end{array}$} & Tamil $(n=75)$ & $1.27 \pm 0.445$ & \multirow{2}{*}{2.111} & \multirow{2}{*}{$0.036^{*}$} \\
\hline & & English $(\mathrm{n}=100)$ & $1.48 \pm 0.349$ & & \\
\hline \multirow{2}{*}{$\begin{array}{l}\text { Type of } \\
\text { accommoda- } \\
\text { tion }\end{array}$} & \multirow{2}{*}{$\begin{array}{l}\text { GHQ social } \\
\text { dysfunction }\end{array}$} & Hosteller $(n=65)$ & $1.11 \pm 0.312$ & \multirow{2}{*}{2.245} & \multirow{2}{*}{$0.026^{*}$} \\
\hline & & Day scholar $(\mathrm{n}=110)$ & $1.25 \pm 0.432$ & & \\
\hline
\end{tabular}

*statistically significant by student's unpaired independent ' $t$ ' test.

Correlation between mental health and adjustment was done using Pearson's Correlation test. It was found that GHQ somatic symptoms were found to be strongly negatively correlated with AISS educational adjustment score [ $\mathrm{r}=-0.193$; $\mathrm{p}=0.01]$ and AISS overall score $[\mathrm{r}=-0.210 ; \mathrm{p}=0.006]$. GHQ anxiety symptoms score was negatively correlated with AISS emotional adjustment score $[\mathrm{r}=-0.182 ; \mathrm{p}=0.01]$. GHQ social dysfunction showed strong negative correlation with AISS educational adjustment score $[\mathrm{r}=-0.220 ; \mathrm{p}=0.003]$.

\section{Discussion}

The characteristics of a well adjusted person are awareness of his own strengths and limitations, respecting himself and others, adequate level of aspiration, satisfaction of basic needs, absence of critical or fault-finding attitude, flexibility in behaviour, the capacity to deal with adverse circumstances, a realistic perception of the world, a feeling of ease with his surroundings and a balanced philosophy of life [9]. In specific, school adjustment refers to the capacity of a person to respond to the environment of the school which includes curricular and co-curricular activities.

School adjustment describes the well being of the child as they settle into school and is typically measured by children's perceptions or attitudes towards school, their level of anxiety, behaviour in the classroom, and performance on tasks. Adjustment is influenced by family and child factors, children's prior to school experiences, their relationships with peers and the teacher, and aspects of the classroom environment. The important dimensions of adjustment in school includes Adjustment to the building and school routine, Adjustment to academic, co-curricular activities, Psychological adjustment, Adjustment to and within the self and Social adjustment.

The current study revealed that there were significant problems with adjustment and general health among adolescents. Age is one of the most important factors to influence the coping nature for these problems. From this study it is evident that there is significant increase in the social dysfunction score of the GHQ as age advanced. This finding is partially supported by study of Sharma et al [10] who reported that boys and girls had better mental health during early adolescence (13years), while boys in late adolescence showed better mental health than girls.

A study by Irshad Ali [11] showed that both adolescent boys and girls have high adjustment problems in various areas like: family, school, social and personal front. There was poor adjustment as age increased, with lower ages scoring low and higher ages more with AISS which was contradicted by the study of Hunshal et al (2007) [12]), while Rajeswari et al (2013) [13] and Emmanuel et al (2013) [14] found no relation with age and adjustment. This poor adjustment as age advances is due to the increase in academic responsibilities and parental pressure and expectations on their children's performance, social responsibilities and role to be played in each stage getting complicated.

This study showed no gender differences in the prevalence of adjustment problems and their coping similar to Maureen et al [15].

This is in contradiction with the results of Paramanik et al [16] and Kaur et al [17] who stated that girls have better coping with the adjustment problems than boys and hence their academic achievement were better. The gap in the current study on gender differences may be due to the smaller sample size. 
In the analysis of the school-related factors, it was found that the students of government school showed more somatic symptoms than private school students. The current study showed poor educational adjustment among private school students than government school students. This finding is supported by study of Akbar Hussain et al 12 (2008) [18], while Raju et al [19] and few other studies $[20,21]$ showed better emotional and social adjustment in private school students. The poor educational adjustment in private school students may be due to academic stress and pressure.

In this study, students from English medium had significant social dysfunction when compared to those from Tamil medium. Srivastava et al (1999) [22] showed Hindi medium children showing better mental health than children of English medium which supports our finding.

Our study showed no significant difference in adjustment between students of different medium of instruction. However, Raju et. Al [19] showed that students with telugu medium had social adjustment problems compared with students with English as their medium of instruction.

Day scholars showed poor social dysfunction, while hostellers showed poorer social and overall adjustment. This may be due to the fact that children in hostels lack the emotional attachment, direct care and guidance from their parents and other close relatives, while day scholars may not get the opportunity to share their problems with peers and also lack independency in decision making.

This strong correlation of scores suggests that as mental health declines, coping to stress declines which leads on to diverse adjustment problems. This view was supported by various studies [23, 24, 25].

\section{Conclusion}

In our study, it is clear that adolescence is the vulnerable period for various adjustment problems and factors like increasing age, type of school, medium of instruction and type of accommodation is significantly affecting the coping nature of these adjustment problems. Also, there is a strong negative correlation between GHQ-28 scores and AISS scores denoting that as mental health declines, the ability to adjust also deteriorates. Early identification and education is essential to successfully overcome these problems and to promote healthy adolescence.
Funding: Nil, Conflict of interest: Nil

Permission from IRB: Yes

\section{References}

1. Arnett JJ. Adolescent storm and stress, reconsidered. Am Psychol. 1999 May;54(5):317-26.

2. Adolescence - an Age of opportunity. available at http:// www. unicef.org/ india/ media_6785.htm, last accessed on 14/071/2014.

3. World Health Organization. Dept. of Mental Health, Substance Abuse. Mental health atlas 2005. World Health Organization; 2005.

4. Malhotra S, Patra BN. Prevalence of child and adolescent psychiatric disorders in India: a systematic review and meta-analysis. Child Adolesc Psychiatry Ment Health. 2014 Jul 21;8:22. doi: 10.1186/17532000-8-22. eCollection 2014.

5. Menninger, K.A., 1945, Human kind. New York. $3^{\text {rd }}$ edition. John Willey Publications.

6. Klein DB. Mental hygiene: a survey of personality disorders and mental health. Holt; 1956.

7. Sinha AK, Singh RP. Manual for adjustment inventory for school students. National Psychological Co, Agra. 1984.

8. Goldberg DP, Hillier VF. A scaled version of the General Health Questionnaire. Psychol Med. 1979 Feb; 9(1):139-45.

9. Mangal S. Advanced educational psychology. New Delhi, India: PHI Learning; 2012.

10. Sharma RR. Self-concept, level of aspiration and mental health as factors in academic achievement. Cited in Third Survey of Research in Education (1978-83), New Delhi: NCERT. 1979;688.

11. Irshad Ali Dhar, Latief Ahmad Tali. Adjustment Problems among Kashmiri Adolescents. International Journal of English, Language, Literature and Humanities. 2014. Vol 1;4: 99-107.

12. Hunshal SC, Gaonkar V. A study on adjustment of institutionalized children. Karnataka Journal of Agricultural Sciences. 2010 May 21;21(4). 
13. Rajeswari S, Eljo JO. A Study on Emotional Adjustment of Adolescent School Students. International Journal of Humanities Social Sciences. 2013 May;2(2):49-56.

14. Emmanuel D. Adjustment among School going Adolescents: A Study in Kunnathur village, Annur Block (Coimbatore District). International Journal of Humanities and Social Science Invention. January 2013; Volume 2(1):07-12

15. Adhiambo WM, Odwar AJ, Mildred AA. The relationship among school adjustment, gender and academic achievement amongst secondary school students in Kisumu district Kenya. Journal of emerging Trends in Educational research and policy studies. 2011;2(6):493-7.

16. Paramanik J, Saha B, Mondal BC. Adjustment of Secondary School Students with Respect to Gender and Residence. American Journal of Educational Research. 2014 Jan 23;2(12):1138-43.

17. Kaur S. A study of adjustment of high school students in relation to their achievement, sex and locality. International Journal of Research in Education, Methodology Council For Innovative Research. 2012; 1(2):18-21.

18. Hussain A, Kumar A, Husain A. Academic stress and adjustment among high school students. Journal of the Indian Academy of Applied Psychology. 2008 Apr;34(9):70-3.
19. Raju MV, Rahamtulla TK. Adjustment problems among school students. Journal of the Indian academy of applied psychology. 2007 Jan;33(1):73-9.

20.Yellaiah A study of adjustment on academic achievement of high school student. International Journal of social science and interdisciplinary research 2012 Vol.1 No.5 ISSN 22773630.

21. Pradhan GC. Values pattem of school students as a function of types of schools and levels ofintelligence. The Educational Review. 1992;92:133-6.

22. Srivastava, S. K., Prasad, Deepesh chand and kumar, vipin. A study of mental health of hindi and English medium students'. J. Edu. Res. Extn. , 199936 (3) : 23-28.

23. Abraham M. A study of certain psycho-social correlates of mental health status of university entrants of Kerala. Kerala (Psychology). 1985.

24. Yeh CJ. Age, acculturation, cultural adjustment, and mental health symptoms of Chinese, Korean, and Japanese immigrant youths. Cultural Diversity and Ethnic Minority Psychology. 2003 Feb;9(1):34.

25. Bharadwaj SK, Helode RD. School adjustment as a function of neuroticism and gender of the adolescents. Indian Psychological Review. 2006;66(1):25.

\section{How to cite this article?}

Rajkumar G, Saravanan M, Anbarasi M. Effect of Academic-related Factors on Adjustment Problems in Adolescents.Int .J Pediatr Res.2016;3(9):683-688.doi:10.17511/ijpr.2016.i09.10. 